\title{
Getting emotional about data The soft side of data management services
}

$\mathbf{W}$ e've all had that moment when you make a connection, your patrons' eyes light up and they have an "aha" moment. As a data management services librarian, I have had many conversations with researchers who are in search of that moment. However, too often the conversation starts in a negative place, making it harder for researchers to hear my message. At a recent workshop, one faculty member stated that he didn't believe in "all that altruistic stuff." However, by the end, he looked up from his phone at the idea that he could get credit for sharing data, just like he gets credit for his other scholarship. The spark in his eyes indicated that he had at least started to listen.

Over the years, I have asked myself, "Why so negative a reaction?" While researchers may be suffering from a lack of time, changing expectations, and a plethora of misinformation about data management, I come with solutions. So why the push-back? Certainly, not every researcher responds negatively, but at nearly every workshop there is at least one. This may be due to any number of reasons: the increasing administrative burden of getting funding, lack of adequate data management practices, lack of time to accommodate change, lack of technological solutions, resentment of greater oversight and accountability, or even just having a bad day. Whatever the reason, negative reactions regarding data management complicates communication about the topic.

It wasn't until I was flipping through pictures that I had taken from a "Day of Data" event that I saw an image that speaks to the heart of the matter. This "Day of Data" took place at the Institute for Computational and Experimental Research in Mathematics at Brown University, and was held to "re-engage faculty in the data culture- to inform, prepare, and enable them to address societal, technical and research challenges together." ${ }^{1}$ Brown is not the only institution that has had such events, as it is becoming more commonplace for universities to host data-focused events. ${ }^{2,3,4}$ As researchers spoke, others could respond via postcards. One anonymous researcher sketched a gun that shot out the word "data" and from that, the emotions "fear," "sadness," "love," "happy," and "angst." This image eloquently articulates that data can dictate a researcher's success or failure, and as such, is fraught with a full spectrum of emotion.

However, there is little written regarding this emotional component of research data management. Even with regards to librarianship, "The affective paradigm ... has emerged in the past few years to address some of the emotional aspects of information seeking and sharing, but it fails to deal meaningfully with the feelings of the researcher." ${ }^{5}$ Perhaps for this reason, comments about how researchers

Amanda K. Rinehart is data management services librarian at The Ohio State University, email: rinehart.64@osu.edu

Contact series editors Adrian Ho, director of digital scholarship at the University of Kentucky Libraries, and Patricia Hswe, digital content strategist at Penn State University, at crlnscholcomm@gmail.com with article ideas

(c) 2015 Amanda K. Rinehart 
feel about their data tend to appear in informal venues. In one forum on researcher frustration, Beth Hutton ${ }^{6}$ states:

You have to find some way to let go of your disappointment that your hypothesis was wrong and let the data lead you to a new level of understanding. . . Ultimately, if you want to be a happy scientist, you will need to learn to be joyful whilst also being wrong much of the time. Perhaps you are instead a historian (or whatever), but I do believe many of the same principles apply.

While I have yet to discover why researchers do not readily acknowledge that research, and the data that underpins that research, has emotional connotations, I have found that using active listening skills minimizes negativity during consultations. "Active listening involves six skills: paying attention, holding judgement, reflecting, clarifying, and summariz-

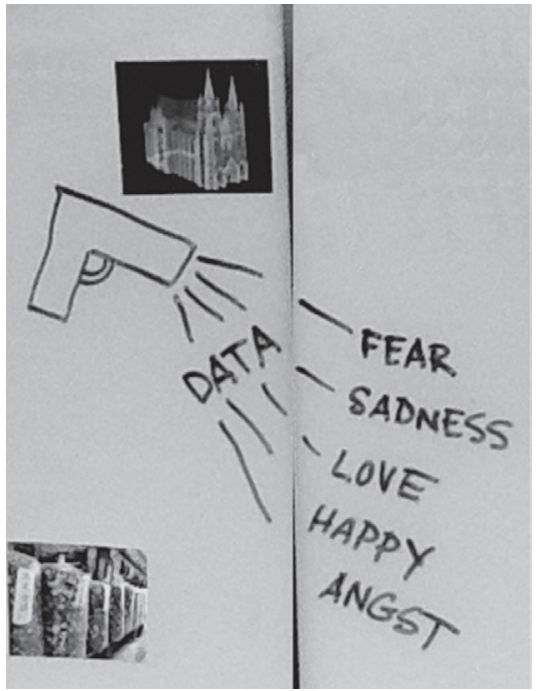
about their data.
Anonymous response to researchers talking ing and sharing."

This is similar to the traditional reference interview in that it is a "conversation between a member of the library reference staff and a library user for the purpose of clarifying the user's needs and aiding the user in meeting those needs." However, active listening typically takes more time than the reference interview and involves more explicit feedback. While it can be tempting to jump directly to pertinent library services (particularly if the researcher appears impatient or has a looming deadline), this may actually inhibit the active listening process and subsequently the understanding of a researcher's true needs.

Although negative emotions may be readily apparent during data management con- sultations, these emotions typically remain unacknowledged until trust is established. For example, in the case of a particularly complex Data Management Plan (DMP) consultation, the grant reviewers had sent the principal investigator (PI) a request for additional information regarding the DMP. ${ }^{9}$ In the ensuing flurry of emails, the PI participated only intermittently and at times ignored or delegated my communications to a junior partner at another institution. From these actions, and the content of the inadequate DMP, I inferred that the PI might be feeling some stress regarding her data management practices. Instead of immediately attempting to engage her in a discussion about changing these practices, I established trust by using my active listening skills while I addressed her immediate needs. In the end, the researcher's final email revealed the reasons for her initial curtness. To demonstrate, I've mapped the stages of active listening to excerpts from my emails during this transaction.

In the end, this research group decided to deposit their data in our institutional repository and the PI sent me the following:

Thanks sooo much for all of your help with this. I was having a mini-panic attack when I saw the request for clarification. ... This is certainly out of the realm of my normal stuff. . . I write a lot of proposals and I have asked [my college] if we have any "standard" types of wording for DMP and no one ever answers my emails. It's been frustrating.

I became trusted enough that this researcher was comfortable revealing her vulnerability and frustration. She knew from my commu- 


\section{My responses}

"Certainly,I would be happy to assist.As I am currently at a conference, I will not be able to respond in detail until [insert date here]."

"It is also helpful if you could send me a copy of the original data management plan. Please don't worry about its current content, I am completely confidential and used to responding to these requests for additional information."

"If I understand the grant reviewers correctly, they are referring to an appropriate repository, which may be an institutional repository or a trusted domain repository. We have an institutional repository at OSU (Knowledge Bank) that is free, but it is entirely open access (i.e., it lacks a mechanism for restricted data use agreements, which may, or may not, be desired).A second option is for this type of data is ICPSR, a very wellestablished data repository for social science research. OSU is a member, which may make depositing your data free of charge, but I recommend contacting themASAP to ensure that it falls within their collection scope and understand the fee structure."

\section{Active listening stage}

Pay attention: By replying within 24 hours and providing a timeline, I reassured her that I was ready and willing despite not being able to respond substantially for two days.

Hold judgement: While few researchers have voluntarily articulated concerns about confidentiality, this statement acknowledged the sensitivity of this information and assured her that I would not expose her to criticism.

Reflect and clarify: Reflecting on the specifics of the request allowed me to break it down into actionable items, and to detail the researchers' options. Often this is the stage where there is a lot of back-and-forth, as the researchers consider their specific preferences and I continue to clarify how various options may meet the requirements. By detailing the pros and cons of each potential, I am established as an unbiased information provider.
"I've added just a few comments, but please don't let me alter your intentions in any way. If you have questions about anything I added, just let me know. Overall, it looks very good and should give the review board exactly what they are looking for."

"Would you mind if I share this incident with others? This is a perfect example of how a lack of data management services is making it hard for researchers to meet these new expectations. I will redact your name, but it's pretty specific, so people might be able to identify you." In the next consultation: "You're not alone - I've been seeing these comments from review boards recently."
Summarize: In my final -mail, I affirmed the researcher's new data management plan, noted any last suggestions, and reiterated our goal (to respond appropriately to the review board). I also reminded the researcher to reach out to me for further assistance.

Share: After our successful interaction, I asked the researcher if I may share her experience with others. 
nications that I did not judge and that I could help her establish better (if not best) practices. By engaging active listening skills, I relieved tensions surrounding this situation, even though I had not known about her previous unsuccessful attempts to learn about DMPs.

Active listening is not new to librarianschances are, if you have handled a difficult reference question or facilitated a beloved donation, you have used some (or all) of these skills. As well, people's deep emotional attachment to what they possess is not new to librarians either. Megan Garbett-Styger ${ }^{10}$ notes that it is:

\begin{abstract}
important for the archivist to remember that the anger, frustration, or sadness that the donor may express is not his or her fault... It is best to not take these reactions personally and try to empathize with the donor. Sometimes taking the time to listen, even when you do not necessarily have it, is part of the job when working with people
\end{abstract}

By deliberately applying active listening skills, any librarian or archivist can create a safe environment for researchers to express their concerns about their data. In my experience, implementing better data management practices may be less about the material and technology, and more about the people. When detailing what librarians can contribute, we typically cite the ability to "identify, describe, locate, share and preserve large amounts of data." ${ }^{11}$ We should add to this that librarians bring a deep understanding of how people interact with information. This understanding has resulted in an abiding code of ethics that includes the commitment to privacy and confidentiality; it makes librarians safe confidants. ${ }^{12}$ Actively listening promotes this trusting relationship and increases the likelihood that researchers will seek out librarians to learn about data management.

\section{Notes}

1. The Digital Society, "May 18: Day of Data," The Digital Society, last modified May 10, 2012, www.brown.edu/research/projects /digital-society/news/2012-05/may-18-daydata (accessed August 7, 2015).

2. Stanford University, "Data Day 2015," Standford University Libraries, https://dataday. stanford.edu/ (accessed August 7, 2015).

3. Yale University, "Yale Day of Data 2015," EliScholar, http://elischolar.library.yale.edu /dayofdata/2015/ (accessed August 7, 2015).

4. The Ohio State University, "Big Data Future: Free Public Conference," Decision Sciences Collaborative, https://decisionsciences. osu.edu/events/big-data-future-free-public -conference (accessed August 7, 2015).

5. Archie Dick, "What we don't (but should) teach young researchers," Information development 29, no. 3 (2013): 197-199. DOI: $10.1177 / 0266666913494047$.

6. Beth Hutton, "How do I deal with frustration in research?" Quora, www.quora.com /How-do-I-deal-with-frustration-in-research (accessed August 7, 2015).

7. Michael Hoppe, An ideas into action guidebook: Active listening: Improve your ability to listen and lead (Greensboro, NC: Center for Creative Leadership, 2006), Chapter 2, http://proquest.safaribooksonline. com/book/communications/9781882197941 /the-active-listening-skill-set/the_active _listening_skill_set?uicode $=$ ohlink .

8. R. E. Bopp and L. C. Smith, Reference and Information Services: An Introduction, 2nd ed. (Englewood, Colorado: Libraries Unlimited, 1995), 36.

9. Amanda Rinehart, "Data Tales from the Hills: The Request For Information (RFI)," Databrarians, June 24, 2015, http://databrarians. org/2015/06/data-tales-from-the-hills-the -request-for-information-rfi/.

10. Megan Garbett-Styger, "Death, dying and archives: Learning to work with grieving and dying donors" (Masters Thesis, Western Washington University Masters Thesis Collection, 2014), 76.

11. Joyce Ray, Research Data Management: Practical Strategies for Information Professionals (Indiana: Purdue University Press, 2014), 29.

12. ALA, "Code of Ethics of the American Library Association," January 22, 2008, www.ala.org/advocacy/proethics/codeofethics /codeethics. n 